\title{
Lap joint dissimilar welding of aluminium AA6061 and galvanized iron using TIG welding
}

\author{
L.H. Shah ${ }^{1,2^{*}}$, U.K. Mohamad ${ }^{1}$, K.I. Yaakob ${ }^{1}$, A.R. Razali $^{1}$ and M. Ishak $^{1}$ \\ ${ }^{1}$ Faculty of Mechanical Engineering, Universiti Malaysia Pahang, \\ 26600 Pekan, Pahang, Malaysia. \\ *E-mail: luqmanhakim@ump.edu.my \\ ${ }^{2}$ Department of Mechanical and Mechatronics Engineering, \\ University of Waterloo, 200 University Avenue West, \\ Waterloo, Ontario, Canada, N2L 3G1. \\ Phone: +609-424-6234
}

\begin{abstract}
In this paper, aluminium AA6061-O and galvanized iron were lap-joined using tungsten inert gas (TIG) welding. The experiments were conducted using Si-rich filler metals ER4043 (Si 5 wt.\%) and ER4047 (Si 12 wt.\%). The mechanical properties and the microstructure of the samples were analysed using dye penetrant non-destructive tests (NDT), optical microscope observation and shear tests. All samples showed good quality joints, with Al-GI specimens showing better quality. Through optical microscope observation, the intermetallic compounds (IMC) of specimens using ER4043 fillers show a thin IMC layer ranging from $4 \mu \mathrm{m}$ to $7 \mu \mathrm{m}$, compared to ER4047 samples which ranged between $20 \mu \mathrm{m}$ and $40 \mu \mathrm{m}$. The shear tests show that the GI-Al group fractured at the IMC layer, while the Al-GI group fractured at the FZ-HAZ aluminium matrix. The highest shear strength value obtained was $89.82 \mathrm{MPa}$ and $76.59 \mathrm{MPa}$ for the Al-GI and GI-Al positions, respectively. It can be concluded that the GI-Al (galvanized iron on top and aluminium at the bottom) configuration with filler type ER4043 (Si 5 wt.\%) has the optimum mechanical properties with a thin IMC layer and tensile strength of $76.59 \mathrm{MPa}$.
\end{abstract}

Keywords: Dissimilar welding; TIG welding; aluminium; galvanized iron; microstructure; mechanical properties.

\section{INTRODUCTION}

Welding is used throughout industry, in building construction, aircraft manufacturing, and for automobile production. Due to its strength and versatility, welding is applied in the manufacturing of almost all the products used in our everyday lives [1-4]. One of the commonly used welding techniques is tungsten inert gas (TIG) welding, an arc welding process using an outer filler rod inserted manually with a shielding gas to protect the arc between a non-consumable tungsten electrode and the weld area [5]. Dissimilar welding, i.e. welding between metals of different types or grades, is a growing requirement in the welding sector [6-9]. It is a very challenging process due to the significant difference in the material properties. A lot of research has been done and reported on dissimilar welding [10-12]. Arguably the most famous research is on welding between aluminium and steel [2, 13-18]. The advantages include low cost and a weight-optimization body with high stiffness, reduction of material waste and energy 
saving [19]. To date, aluminium-steel welding has been performed using a vast number of welding methods, which include arc welding [15, 19-21], laser welding [22] and friction stir welding (FSW) [23]. In arc welding of aluminium-steel, previous studies show that tungsten inert gas (TIG) is preferable to metal inert gas (MIG) welding. This is because $[12,15,23,24]$ : the TIG arc is stable even at low currents, making welding of thin parts possible; it produces a very good weld quality, and is an ideal candidate for aluminium welding. However, due to the large difference between their melting points, the nearly zero solid solubility of iron in aluminium, and the formation of brittle intermetallic compounds (IMC) such as $\mathrm{Fe}_{2} \mathrm{Al}_{5}$ and $\mathrm{FeAl}_{3}$, the difficulty in its fabrication becomes twofold [15, 20, 25, 26]. Utilizing galvanized iron (GI) as the ferrous base metal has been shown to facilitate aluminium-steel welding. This can be attributed to the existence of a thin Zn layer on the GI surface. This layer assists in the welding process because $\mathrm{Zn}$ has good metallurgical compatibility with both aluminium and steel $[15,20,27,28]$. Other than that, many researchers have also pointed out that the base and filler metal elements have a significant effect on the joint strength [29-31]. In this study, a detailed investigation on aluminium-galvanized iron dissimilar welding is conducted. The materials will be lap-joined together by a TIG welding process using different filler rods, which are ER4043 and ER4047. Mechanical and microstructural characterization will then be conducted to observe the weld joints' quality and morphology.

\section{EXPERIMENTAL SETUP}

\section{Material Preparations}

The base materials used in this research are AA6061-O aluminium alloy and galvanized iron plates with a thickness of $2 \mathrm{~mm}$. Both types of plate were cut into $100 \mathrm{~mm} \times$ $50 \mathrm{~mm}$ using a MVS-C 6/31 shearing machine. The filler metals utilized were Si-rich ER4043 (5 wt.\%) and ER4047 (12 wt.\%) filler rods. The chemical composition of the base materials and filler metals is shown in Table 1 and Table 2, respectively.

Table 1. Material composition in wt.\%.

\begin{tabular}{cccccccccc}
\hline Elements & $\mathrm{Cu}$ & $\mathrm{Si}$ & $\mathrm{Mn}$ & $\mathrm{Mg}$ & $\mathrm{Cr}$ & $\mathrm{C}$ & $\mathrm{P}$ & $\mathrm{S}$ & $\mathrm{Fe}$ \\
\hline AA6061 & 0.205 & 0.680 & 0.083 & 0.884 & 0.167 & - & - & - & 0.404 \\
Steel & 0.0083 & $<0.005$ & 0.286 & - & 0.084 & 0.068 & 0.028 & 0.029 & 98.6 \\
\hline
\end{tabular}

Table 2. Filler metal composition in wt.\% [32].

\begin{tabular}{ccccccccc}
\hline Elements & $\mathrm{Si}$ & $\mathrm{Fe}$ & $\mathrm{Cu}$ & $\mathrm{Zn}$ & $\mathrm{Mn}$ & $\mathrm{Mg}$ & $\mathrm{Ti}$ & $\mathrm{Al}$ \\
\hline ER4043 & $4.5-6.0$ & $<0.80$ & $<0.30$ & $<0.10$ & $<0.05$ & $<0.05$ & $<0.20$ & $\mathrm{Bal}$ \\
ER4047 & $11.0-13.0$ & $<0.80$ & $<0.30$ & $<0.20$ & $<0.05$ & $<0.10$ & - & Bal \\
\hline
\end{tabular}

\section{TIG Welding Process}

After the cutting process, the aluminium 6061 was lap-joined to the galvanized iron using the commercially available Miller Dynasty 200 TIG arc welding machine. The process was carried out by using AC-TIG welding sources with the welding current fixed at 50 A. Figure 1 shows the TIG welding process. To position the top material in place, an additional plate with the same thickness was stacked at the bottom of the top plate and fixed accordingly. In order to find the optimum variables, several types of 
conditions were investigated. In order to differentiate the results, the specimens were coded based on the variable parameters, which are the type of filler used and the material positioning for lap joining (as the top metal or bottom metal, as in Figure 1). Two samples were welded for each designated code. Table 3 shows the designation for the filler metal and material position.

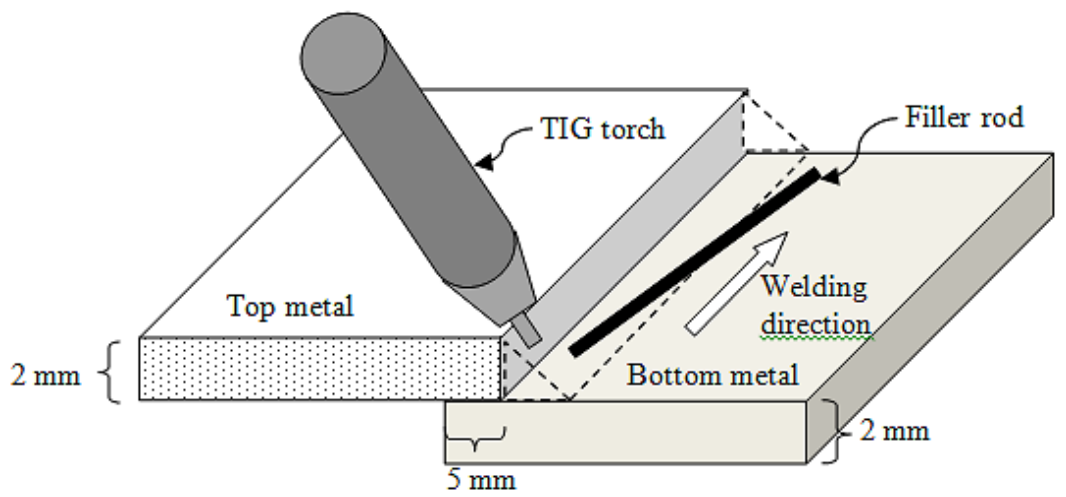

Figure 1. Schematic diagram of the TIG process.

Table 3. Designation for filler metal and material position.

\begin{tabular}{lc}
\hline Filler type with material position & Designation \\
\hline ER4047, Top: aluminium, Bottom: galvanized iron & $7 \mathrm{Al}-\mathrm{GI}$ \\
ER4043, Top: aluminium, Bottom: galvanized iron & $3 \mathrm{Al}-\mathrm{GI}$ \\
ER4047, Top: galvanized iron, Bottom: aluminium & $7 \mathrm{GI}-\mathrm{Al}$ \\
ER4043, Top: galvanized iron, Bottom: aluminium & $3 \mathrm{GI}-\mathrm{Al}$ \\
\hline
\end{tabular}

\section{Macrostructure and Microstructure Analysis}

The weld appearance and microstructure of the specimen were investigated using a dye penetrant non-destructive test (NDT) and an optical microscope, respectively. The NDT test is done to reveal defects that would be difficult or impossible to detect with the naked eye [24]. The test was conducted by first pre-cleaning the weld surface using a cleaner. Next, the red dye penetrant was sprayed on the surface and left for several minutes to allow penetration into any surface defects. The excess penetrant was then removed from the weld surface using a table cloth. Lastly, a white developer was sprayed in order to draw out the red penetrant from the defects to pinpoint distinct surface defect locations. After the dye penetrant test, the samples were sheared perpendicular to the weld bead to expose the cross-section of the joint. A ProgRes C3 IM7200 optical microscope was used to examine the samples. The microscopic images for analysis were taken using $10 \times$ and $50 \times$ magnifications.

\section{Fracture and Mechanical Property Analysis}

Shear tests were used to evaluate the shear strength of the welded specimens. The aluminium-galvanized iron samples were pulled to failure at a constant rate. The test was carried out by the INSTRON tensile test machine and the samples were prepared with reference to the ASTM E8-09 standard [33, 34]. The fracture mechanics were also analysed after the shear test. 


\section{RESULTS AND DISCUSSION}

\section{Weld Appearance}

Table 4 shows the weld appearance and outer defects detection using the dye penetrant NDT method. Major defects, i.e. the regions marked with red, were observed primarily at the start and end of the welding, which is unavoidable in manual welding. However, the overall weld beads showed a good quality finish. The Al-GI group specimens show good bead continuity and the best weld appearance due to minimal surface defects. Defects such as cracks, porosity, cavities and a lack of fusion can constitute a cause of decreased joint strength and integrity [35]. The prominent defect that occurred on the specimens is the existence of pores, particularly in the GI-Al group specimens. Porosities were easily formed in deeply penetrated weld beads. Since a low welding speed was detrimental to ensuring good brazing on the steel surface, the trapped air bubbles generated from the electrode tip during welding formed the porosities observed [36].

Table 4. NDT test of welded specimens.

\begin{tabular}{ccc}
\hline Designation & Sample 1 & Sample 2 \\
\hline 7Al-GI & Al & Al \\
& GI & GI \\
3Al-GI & Al & Al \\
& GI & GI \\
& GI & GI \\
7GI-Al & Al & Al \\
& GI & GI \\
\hline 3GI-Al & Al \\
\hline
\end{tabular}

\section{Microstructure and Mechanical Properties}

Figure 2 shows the cross-section and microstructure of the 3GI-Al specimen with the type of microstructure formations. The macrostructure shows a welding-brazing interaction, since enough heat input was induced in the weld area to melt the aluminium base metal, but was not sufficient for the steel counterpart [29]. As shown in 
Figure 2(d), the galvanized iron base metal contained a ferrite structure which was formed during the rapid cooling phases. Meanwhile, the aluminium base metal in Figure 2(e) contained the formation of heterogeneous nuclei. In the aluminium fusion zone (FZ) (Figure 2(a)) and the heat-affected zone (HAZ; Figure 2(f) and 2(h)), the formation of dendrites can be seen. The dendrite fragmentation is carried into the bulk weld pool and the dendrites act as nuclei for new grains to form [37]. Figures 2(b), 2(c) and $2(\mathrm{~g})$ show the formation of an intermetallic compound (IMC) layer at the faying surface of the two metals, which will be discussed below.

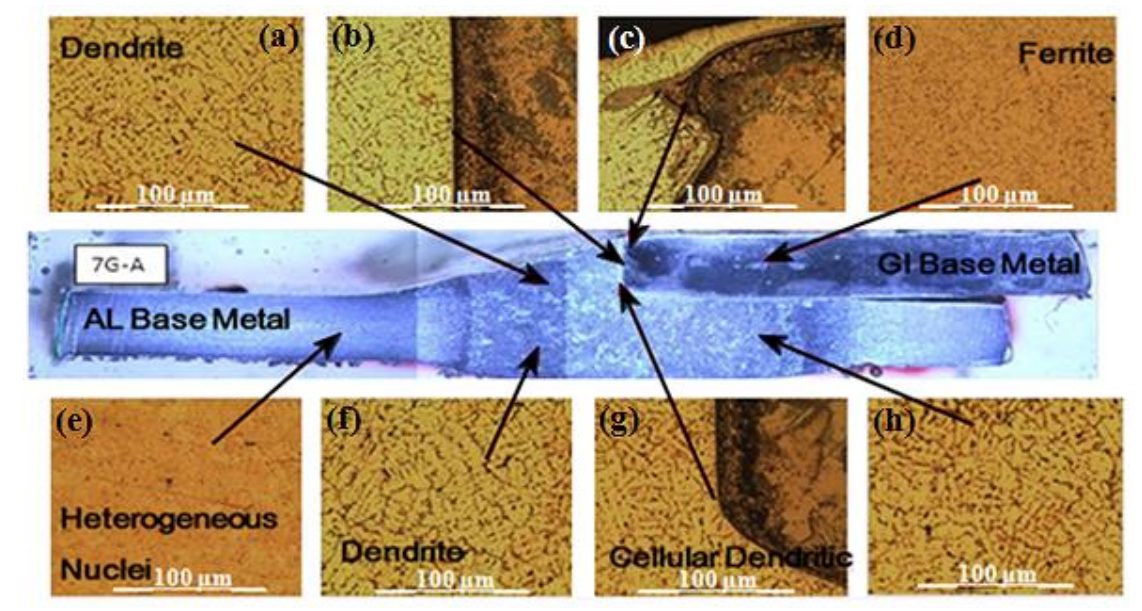

Figure 2. Cross-section and microstructure of the 3GI-Al specimen: (a) aluminium FZ, (b) IMC (middle part), (c) IMC (upper part), (d) steel base metal, (e) aluminium base metal, (f) aluminium HAZ, (g) IMC (lower part), (h) aluminium HAZ.

Figure 3 shows the IMC layers of the four groups with $50 \times$ magnification. Figures 3(b) and 3(d), which utilized filler ER4043, have a thinner IMC layer, with values measured between approximately $4 \mu \mathrm{m}$ and $7 \mu \mathrm{m}$ compared to Figures 3(a) and 3(c), which used filler ER4047 and had values between approximately $20 \mu \mathrm{m}$ and 40 $\mu \mathrm{m}$. A thicker IMC layer will have a detrimental effect on the strength of the weld specimens due to its brittle nature and potential crack initiation region [32]. Therefore, mitigation of IMC layer formation will produce a higher tensile strength and better weld joint. Kreimeyer and Sepold [38] stated that, for an IMC layer less than $10 \mu \mathrm{m}$, the assemblies present sound joint and high interface strength. Si additions in the filler metal have been reported to effectively prevent the growth of an IMC layer [29]. However, previous reports indicate that $\mathrm{Si}$ has a $0.8-6 \mathrm{wt}$ \% solubility in the Al-Fe IMC system [35, 36]. Therefore, a higher Si percentage such as in ER4047 (Si 12\%) will induce a supersaturated solid solution in the IMC layer during the rapid cooling, which causes the phase hardness to increase, consequently decreasing the shear strength, as will be evident in the mechanical section below [29]. 


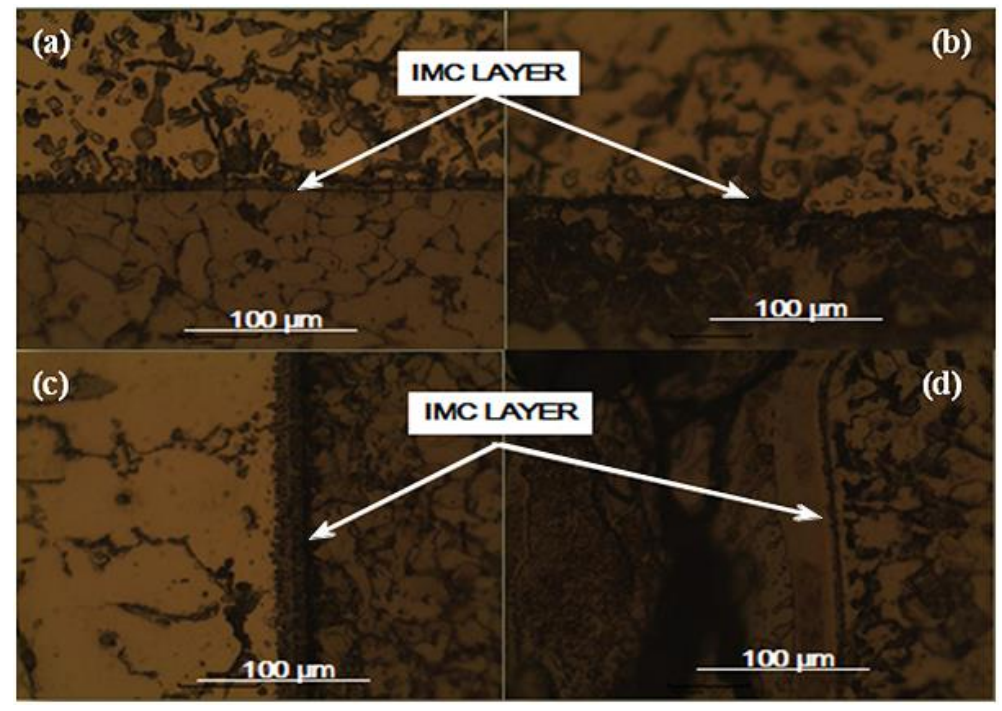

Figure 3. IMC layer with 50× magnification for (a) 7Al-GI, (b) 3Al-GI, (c) 7GI-Al and (d) 3GI-Al.

\section{Fracture and Mechanical Properties Analysis}

A shear test was conducted and the fracture specimens are shown in Figure 4. The arrows show the fracture regions seen from the top and side view. Both groups failed at the perpendicular plane with respect to the loading direction. However, close observation reveals a stark contrast of the fracture region of both groups. For the GI-Al group, the fracture occurred at the brittle faying surface, i.e. the IMC layer, while for the Al-GI group the fracture occurred at the ductile aluminium FZ-HAZ region. Numerous reports indicate that dissimilar welding of aluminium-steel will fail at the IMC plane, which correlates with the results of the GI-Al group [21, 27, 30]. However, the Al-GI group failed at the ductile aluminium matrix. It is commonly known that brittle materials generally fail in tension, while ductile materials generally fail in shear [39]. Due to the brittle IMC layer of the Al-GI group being parallel to the loading direction, it withstood the shear loading until the ductile FZ-HAZ region of aluminium, having a smaller cross-sectional surface, yielded [19, 40, 41].
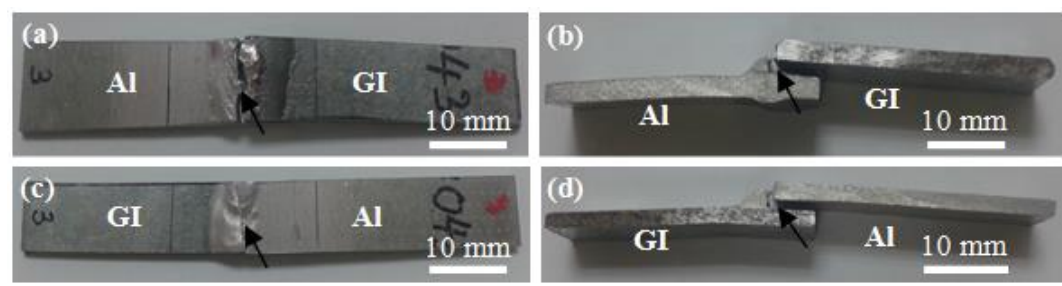

Figure 4. Fracture points for GI-Al (a) top view, (b) side view and Al-GI (c) top view, (d) side view.

The results of the shear test are shown in Figure 5. The overall result indicates that filler metal ER4043 shows a higher tensile value for both Al-GI and GI-Al positions compared to ER4047 filler metal samples. This correlates well with the observed IMC layer thickness, since ER4043 shows thinner IMC layer formation. Comparing both positions, the Al-GI position can be seen as producing better shear strength compared to its GI-Al counterpart, for the reasons given above. Therefore, the 
3Al-GI sample with filler metal ER4043 and Al-GI configuration has the highest tensile value of $89.82 \mathrm{MPa}$. For the GI-Al group, the highest tensile strength obtained is $76.59 \mathrm{MPa}$ from the $3 \mathrm{GI}-\mathrm{Al}$ sample. As a reference, the values were compared to similar aluminium AA6061-O welding. The shear strength obtained was $107.2 \mathrm{MPa}$ and 75.85 MPa for filler metals ER4043 and ER4047, respectively. This clearly shows that the shear values for similar aluminium welding are higher than for dissimilar welding specimens. This is due to the absolute solubility between the base metals of aluminium during welding, compared to the welding-brazing nature of aluminium-galvanized iron dissimilar welding.

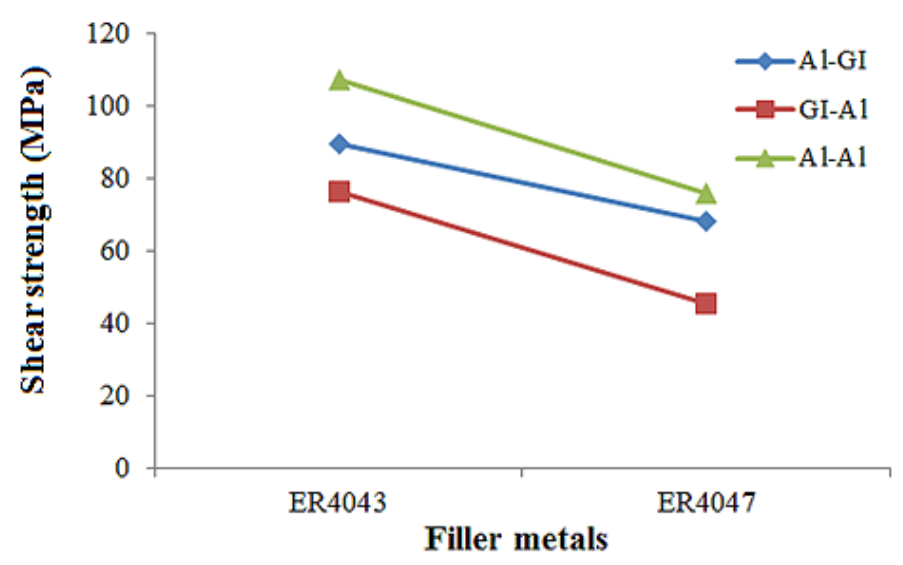

Figure 5. Tensile shear strength of the weld joint with different positions and filler types.

\section{CONCLUSIONS}

In this paper, an attempt was made to investigate the lap joint TIG dissimilar welding of AA6061-O and galvanized iron using various filler metals and base metal positioning. An NDT test was conducted on the welded specimens to observe the joint quality. Overall, the weld beads for all specimens showed a good quality finish, with Al-GI specimens showing better quality. For the microstructure characterization, the GI-Al positions with filler type ER4043 showed a thin IMC layer in the proximity of $7 \mu \mathrm{m}$. Shear tests were conducted in order to measure the lap joint shear strength values. The GI-Al group fractured at the IMC layer, while the Al-GI group fractured at the FZ-HAZ aluminium matrix. The highest shear strength values obtained were $89.82 \mathrm{MPa}$ and 76.59 $\mathrm{MPa}$ for the Al-GI and GI-Al positions, respectively. It can be concluded that the GI-Al configuration with filler type ER4043 ( $\mathrm{Si} 5 \mathrm{wt} . \%$ ) has the optimum mechanical properties, with a thin IMC layer and a tensile strength of $76.59 \mathrm{MPa}$. However, this experiment is restricted to only a few specimens and limited welding parameters. The joint strength can be further enhanced in the future by additional parameter optimization, including other welding variables, using an automated welding machine, as well as proper customized jig fixtures to ensure a better weld quality finish.

\section{ACKNOWLEDGEMENTS}

The authors would like to thank Universiti Malaysia Pahang for the RDU120341 and RDU130344 research grants. 


\section{REFERENCES}

[1] Saunders FI, Wagoner RH. The use of tailor welded blanks in automotive application. In: Dawson P, Shen S-F, editors. Simulation of materials processing: theory, methods and applications: Proceedings of the 5th international conference NUMIFORM. Ithaca, New York: Taylor \& Francis; 1995. p. 157-64.

[2] Chan S, Chan L, Lee T. Tailor-welded blanks of different thickness ratios effects on forming limit diagrams. Journal of Material Processing Technology. 2003;132:95-101.

[3] Kinsey B, Viswanathan V, Cao J. Forming of aluminum tailor welded blanks. SAE Technical Paper; 2001.

[4] Tušek J, Kampuš Z, Suban M. Welding of tailored blanks of different materials. Journal of Materials Processing Technology. 2001;119:180-4.

[5] Moniz B, Miller R. Welding Skills. Stockton, CA, USA: Recording for the Blind \& Dyslexic; 2007.

[6] Wor LC, Rahman MM. Stress behavior of tailor-welded blanks for dissimilar metals using finite element method. International Journal of Automotive and Mechanical Engineering. 2015;11:2541-54.

[7] Ishak M, Noordin NFM, Razali ASK, Shah LHA, Romlay FRM. Effect of filler on weld metal structure of AAa6061 aluminum alloy by tungsten inert gas welding. International Journal of Automotive and Mechanical Engineering. 2015;11:2438-46.

[8] Ghazali FA, Manurung YHP, Mohamed MA, Alias SK, Abdullah S. Effect of process parameters on the mechanical properties and failure behavior of spot welded low carbon steel. Journal of Mechanical Engineering and Sciences. 2015;8:1489-97.

[9] Charde N. Characterization of spot weld growth on dissimilar joints with different thicknesses. Journal of Mechanical Engineering and Sciences. 2012;2:172-80.

[10] Sathari NAA, Shah LH, Razali AR. Investigation of single-pass/double-pass techniques on friction stir welding of aluminium. Journal of Mechanical Engineering and Sciences. 2014;7:1053-61.

[11] Ishak M, Shah LH, Aisha ISR, Hafizi W, Islam MR. Study of resistance spot welding between AISI 301 stainless steel and AISI 1020 carbon steel dissimilar alloys. Journal of Mechanical Engineering and Sciences. 2014;6:793-806.

[12] Abd Razak NA, Ng SS. Investigation of effects of MIG welding on corrosion behaviour of AISI 1010 carbon steel. Journal of Mechanical Engineering and Sciences. 2014;7:1168-78.

[13] Fukumoto S, Tsubakino H, Okita K, Aritoshi M, Tomita T. Amorphization by friction stir welding between 5052 aluminum alloy and 304 stainless steel. Scr Mater. 2000;42:807-12.

[14] Zhang H, Liu J. Microstructure characteristics and mechanical property of aluminum alloy/stainless steel lap joints fabricated by MIG welding-brazing process. Materials Science and Engineering A. 2011;528:6179-85.

[15] Hatifi MM, Firdaus MH, Razlan AY. Modal analysis of dissimilar plate metal joining with different thicknesses using MIG welding. International Journal of Automotive and Mechanical Engineering. 2014;9:1723-33. 
[16] Sathari NAA, Razali AR, Ishak M, Shah LH. Mechanical strength of dissimilar AA7075 and AA6061 aluminum alloys using friction stir welding. International Journal of Automotive and Mechanical Engineering. 2015;11:2713-21.

[17] Shah LH, Akhtar Z, Ishak M. Investigation of aluminum-stainless steel dissimilar weld quality using different filler metals. International Journal of Automotive and Mechanical Engineering. 2013;8:1121-31.

[18] Charde N. Microstructure and fatigue properties of dissimilar spot welds joints of AISI 304 and AISI 1008. International Journal of Automotive and Mechanical Engineering. 2013;7:882-99.

[19] Dong H, Hu W, Duan Y, Wang X, Dong C. Dissimilar metal joining of aluminum alloy to galvanized steel with Al-Si. Al-Cu, Al-Si-Cu and $\mathrm{Zn}-\mathrm{Al}$ filler wires. Journal of Material Processing Technology. 2012;212:458-64.

[20] Borrisutthekul R, Mitsomwang P, Rattanachan S, Mutoh Y. Feasibility of using TIG welding in dissimilar metals between steel/aluminum alloy. Energy Research Journal. 2010;1:82-6.

[21] Dong H, Liao C, Chen G, Dong C. Butt joining of aluminum to steel by arc brazing process. Materials and Manufacturing Processes. 2012;27:1392-6.

[22] Sierra G, Peyre P, Beaume FD, Stuart D, Fras G. Galvanised steel to aluminium joining by laser and GTAW processes. Materials Characterization. 2008;59:1705-15.

[23] Bang H, Bang H, Jeon G, Oh I, Ro C. Gas tungsten arc welding assisted hybrid friction stir welding of dissimilar materials Al6061-T6 aluminum alloy and STS304 stainless steel. Materials \& Design. 2012;37:48-55.

[24] Mathers G. The welding of aluminium and its alloys. Cambridge, England: Woodhead Publishing Limited; 2002.

[25] Mandal NR. Aluminium welding. 2nd edition ed. Karagpur, India: Narosa Publishing House; 2005.

[26] Dharmedra C, Rao KP, Wilden J, Reich S. Study on laser welding-brazing of zinc coated steel to aluminum alloy with a zinc based filler. Materials Science and Engineering A. 2011;528:1497-503.

[27] Qiu R, Iwamoto C, Satonaka S. The influence of reaction layer on the strength of aluminum/steel joint welded by resistance spot welding. Materials Characterization. 2009;60:156-9.

[28] Lin SB, Song JL, Yang CL, Fan CL, Zhang DW. Brazability of dissimilar metals tungsten inert gas butt welding-brazing between aluminum alloy and stainless steel with Al-Cu filler metal. Materials \& Design. 2010;31:2637-42.

[29] Song JL, Lin SB, Yang CL, Fan CL. Effects of Si additions on intermetallic compound layer of aluminum-steel TIG welding-brazing joint. Journal of Alloys and Compound. 2009;488:217-22.

[30] Ishak M, Noordin NFM, Razali ASK, Shah LHA, Romlay FRM. Effect of filler on weld metal structure of AA6061 aluminum alloy by tungsten inert gas welding. International Journal of Automotive and Mechanical Engineering. 2015;11.

[31] Ahmad R, Asmael MBA. Effect of aging time on microstructure and mechanical properties of AA6061 friction stir welding joints. International Journal of Automotive and Mechanical Engineering. 2015;11:2364-72.

[32] Song JL, Lin SB, Yang CL, Ma GC, Liu H. Spreading behavior and microstructure characteristics of dissimilar metals TIG welding-brazing of 
aluminum alloy to stainless steel. Materials Science and Engineering A. 2009;509:31-40.

[33] ASTM. Standard test methods for tension testing of metallic materials. Annual book of ASTM standards ASTM. 2010.

[34] Nuraini AA, Zainal AS, Hanim MAA. The effects of welding parameters on butt joints using robotic gas metal arc welding. Journal of Mechanical Engineering and Sciences. 2014;6:988-94.

[35] Blondeau R. Metallurgy and mechanics of welding. Hoboken, New Jersey: John Wiley \& Sons Inc.; 2008.

[36] Katayama S, Kawahito Y, Mizutani M. Elucidation of laser welding phenomena and factors affecting weld penetration and welding defects. Physics Procedia. 2010;5:9-17.

[37] Kou S. Welding Metallurgy. New Jersey, USA: John Wiley \& Sons Inc.; 2003.

[38] Kreimeyer M, Sepold G. Laser steel joined aluminium-hybrid structures. International Congress on Applications of Lasers and Electro-Optics 2002 (ICALEO '02)2002.

[39] Beer FP, Jr ERJ, Dewolf JT, Mazurek DF. Mechanics of materials. 5th edition ed. New York: McGraw Hill Higher Education; 2009.

[40] Zhang HT, Feng JC, He P, Hackl H. Interfacial microstructure and mechanical properties of aluminium-zinc-coated steel joints made by a modified metal inert gas welding-brazing process. Materials Characterization. 2007;58:588-92.

[41] Sun YF, Fujii H, Takaki N, Okitsu Y. Microstructure and mechanical properties of dissimilar Al alloy/steel joints prepared by a flat spot friction stir welding technique. Materials \& Design. 2013;47:350-7. 